\title{
AKULTURASI BUDAYA ISLAM DAN TIONGHOA DALAM ARSITEKTUR MASJID AL IMTIZAJ CIKAPUNDUNG BANDUNG
}

\author{
Soni Sadono ${ }^{*}$, Agus Dody Purnomo ${ }^{2 *}$ \\ Program Studi S1 Seni Rupa ${ }^{1}$, Program Studi S1 Desain Interior ${ }^{2}$ \\ Universitas Telkom \\ Jl. Telekomunikasi Terusan Buahbatu, Sukapura, Kec. Dayeuhkolot, Kota Bandung, Kode Pos 40257 \\ Jawa Barat Indonesia \\ Email: sonisadono66@gmail.com,agusdody@telkomuniversity.ac.id
}

\begin{abstract}
Abstrak
Masjid dengan tampilan bentuk dari akulturasi budaya Islam dan budaya Tionghoa sehingga menghasilkan bentuk yang unik. Penelitian ini mengkaji keberadan masjid tersebut melalui bentuk arsitekturnya dan hasil akulturasi dari dua buday a yang berbeda. Metode penelitian menggunakan deskriptif-analitis. Dari penelitian tersebut dapat diketahui bahwa akulturasi atau percampuran budaya tersebut menghasilkan budaya baru dengan tidak men ghilangkan ciri masing-masing. Arsitektur mas jid yang memiliki beragam percampuran budaya Tionghoa, Is lam dan Arab sebagai bentuk pembauran etnis Tionghoa dengan umat muslim lainnya. Arsitektur tersebut juga dapat memperkaya khasanah bangunan masjid di Indonesia khususnya di kota Bandung.
\end{abstract}

Kata Kunci: masjid, akulturasi, budaya, is lam, tionghoa.

\begin{abstract}
The mosque acculturated with the appearance of Islam and Chinese produces a unique culture. This research examines the mosque through its architecture and cultural acculturation. The research method uses descriptive analytical. The research can be seen that acculturation produces a new culture by not eliminating the characteristics of each. The mosque has a diverse mix of Chinese, Islamic and Arabic culture as a form ofmixing ethnic Chinese with other moslem. The architecture can enrich the repertoire of mosque in Indonesia, especially in the city of Bandung.
\end{abstract}

Keywords: mosque, acculturation, culture, islam, chinese.

\section{PENDAHULUAN}

Sejak abad ke $5 \mathrm{M}$ bangsa Tionghoa sudah mengenal Indonesia (saat itu bernama Nan-hai yang berarti Kepulauan Laut Selatan). Mereka datang kemudian menetap di Indonesia yang saat itu masih berbentuk kerajaan-kerajaan. Dan selama beberapa abad jumlah mereka terus bertambah. Mereka bukanlah kelompok yang homogen namun mereka lebih beragam (Handinoto, 2009:72; Suhandinata, 2009:10). Dari dulu hingga sekarang, orang-orang Tionghoa sudah memiliki andil dalamperkembangan bangsa Indonesia, baik dari segi budaya, seni, ag ama, dan lain-lain. Sejak mereka bermigrasi ke Nusantara kemudian berkembang dan berasimilasi dengan mas yarakat lokal. Maka tidak heran dalam perkembangan budaya di Indonesia, unsur-unsur budaya Tionghoa juga ikut mempengaruhi sehingga melahirkan budaya ban yang berbeda dengan budaya as linya.

Salah satunya yakni perkembangan arsitektur masjid yang mencerminkan akulturasi budaya mereka. Keberadaan arsitektur masjid yang ada di Nusantara memberikan bukti bahwa sejarah arsitektur masjid memiliki keragaman bentuk. Keragaman tersebut diharapkan dapat menjadi referensi untuk perancangan ataupun pembangunan masjid berikutnya sesuai dengan latar belakang budaya masyarakat atau komunitasnya.

Penelitian ini bertujuan untuk lebih mengenal keragaman bentuk arsitektur masjid di Indonesia khususnya di kota Bandung. Selain itu untuk mengetahui sejauhmana hasil akulturasi budaya Islam dan buday a Tionghoa yang diterapkan dalamarsitektur masjid.

Untuk itu kajian ilmiah ini akan membahas tentang akulturasi budaya Is lamdan Tionghoa dalamarsitektur Masjid Al Imtijaz Cikapundung, Bandung dikaji melalui uns ur-unsur budayanya. Unsur budaya tersebut dapat dilihat dari bentuk fisik bangunan masjid, misalnya dariatap masjid, ornamen-ornamen yang ada, serta warna-warna yang digunakan dalam arsitekturnya. 


\section{KAJIAN TEORI}

Kebudayaan berasal dari bahasa Sansekerta yaitu 'buddhayah' yang merupakan bentuk jamak dari 'buddhi' (budi atau akal). Budi mempunyai arti akal, kelakuan, dan norma. Sedangkan 'daya' berarti hasil karya cipta manusia (Koentjaraningrat, 1985). Dengan demikian, kebudayaan adalah semuahasil karya, karsa, dan cipta manusia di mas yarakat. Istilah 'kebu dayaan' sering dikaitkan dengan istilah 'peradaban'. Perbedaannya: kebudayaan lebih banyak diwujudkan dalam bidang seni, sastra, religi, dan moral, sedangkan peradaban diwujudkan dalambidang politik, ekonomi, dan teknologi. Menurut terminologi, kebudayaan adalah himpunan segala usaha dan daya upaya yang dikerjakan dengan menggunakan hasil pendapat budi, untuk memperbaiki sesuatu tujuan dalam rangka mencapai kesempurnaan. Di sisi lain, kebudayaan dapat dikelompokkan kepada bidang-bidang antara lain: filsafat, ilmu pengetahuan, kesenian, kaidahkaidah budaya, bahasa, agama budaya, teknik, ekonomi, politik, pendidikan dan lainnya.

Perkembangan budaya di Indonesia selain terdiri dari beragam suku bangsa, juga tidak lepas dari masuknya pengaruh unsur-unsur kebudayaan dari luar yang datang ke tanah air. Kedatangan bangsa-bangsa lain memperkaya warna kebudayaan Indonesia. Bangsabangsa tersebut antaralain: Arab, Parsi, India, China, dan bangsa Eropa (Roszi, 2018:172; Atno, 2000:1). Dimana Indonesia terletak di tengah-tengah jalur perdagangan strategis yang menghubungkan Laut Tengah dan Cina. Tidak heran jika bangsa-bangsa lain datang ke Indonesia dan berinteraksi kemudian berakulturasi dengan masyarakat setempat.

Akulturasi merupakan proses interaktif dan berkesinambungan yang berkembang melalui komunikasi imigran (pendatang) dengan lingkungan sosio budaya yang baru (Mulyana, 2006:140). Akulturasi atau kontak budaya bias anya terjadi pada dua budaya yang berbeda dan melebur menjadi satu, sehingga menghasilkan adanya budaya baru dan tidak melenyapkan kebudayaan aslinya (Ayuningrum, 2017:130).

Fenomena akulturasi budaya banyak terdapat pada budaya Jawa dan Islam. Al Qurtuby menyebut fenomena ini sebagai Sino-Javanese Muslim Culture atau perpaduan Tionghoa, Jawa, Islam. Bentuk SinoJavanese Muslim Culture salah satuny a dapat terlihat pada beberapa arsitektur masjid (Atno, 2000; Qurtuby, 2017; Suhandinata, 2009:24). Adanya muslim Tionghoa di Indonesia menjadi salah satu faktor terjadinya akulturasi budaya tersebut. Perkembangan
Gorga : Jurnal Seni Rupa

Volume 09 Nomor 02 Juli-Desember 2020

p-ISSN: $2301-5942$ | e-ISSN: 2580-2380

masjid di Indonesia dimulai sejak abad ke-7. Tapi pada abad ke-16, terdapat adaptasi dari bangunan bergaya Hindu-Budha pada bangunan masjid. Ciri khasnya adalah bangunan bertiang tunggal, atapnya peris ai dan bersusun, semakin banyak su sunannya, semakin tinggi kesuciannya. Di Jawa, bentuk-bentuk seperti ini berkembang menjadi tempat ibadah agama Islam. Corak-corak candi juga sangat familiar dalam desain bangunan masjid pada jaman Hindu. Dengan demikian dapat dikatakan bahwa landasan yang menjadi pokok perkembangan masjid adalah kebudayaan lama yang di-Islamkan (Rochym, 1995).

Selain mendapat pengaruh Hindu-Budha yang kuat, ada beberapa masjid di Indonesia yang mengadaptasi gaya masjid di Tiongkok. Menurut Kutoyo arsitektur masjid di Tiongkok memakai langgam klenteng. Langg ambisa diartikan gaya, model, cara. Langg amini terkait dengan suatu ciri, bis a berupa budaya, tokoh, peristiwa sejarah, dan lain-lain. Sebuah karya arsitektur bis a berlanggam Eropa, Tionghoa maupun Nusantara, maka dari itu bangunan masjid di Tiongkok arsitekturnya lebih mirip kelenteng dibandingkan masjid pada umumnya. Kubah dan menara juga agak jarang dipakai karena langgam kelenteng umumnya tidak menggunakan kubah dan menara (Kutoyo, 1999; Atno, 2000:12).

Mengenai bentuk bangunan masjid di Indonesia, sebenarnya tidak ada ketentuan yang mengikat. Biasanya bentuk masjid mengikuti langgam daerah setempat, sehingga lahir bentuk masjid yang bermacam-macam sesuai dengan kebiasaan dan kemampuan masyarakat yang mendirikannya. Daerahdaerah yang kurang mendapat pengaruh Hindu biasanya lebih tajam menonjolkan keaslian arsitektur daerahnya dibandingkan daerah-daerah y ang mendapat pengaruh Hindu. Lama-kelamaan, pola arsitektur daerah inipun berubah. Faktor utamanya adalah karena mendapat pengaruh visual dari masjid-masjid di luar Indonesia. Pengaruh yang sangat terasa terutama pada bentuknya, seperti kelengkapan masjid yang bempa menara dan kubah serta unsur-unsur ornamen bangunannya.

\section{METODE PENELITIAN}

Metode penelitian menggunakan metode kualitatif dimana lebih menekankan pada eksplorasi serta memahami makna. Sedangkan pendekatan yang digunakan dalampenelitian inimerupakan pendekatan interdisiplin yakni ilmu seni rupa, desain, dan sosial budaya. Fokus penelitian dan data yang dikumpulkan berkaitan dengan masalah penelitian. Teknik pengumpulan data berupa observasi, wawancara, dan 
studi literatur. Sumber data diperoleh dari data primer dan data sekunder. Data primer meliputi kegiatan survei di lapangan dan wawancara dengan pengelola maupun narasumber yang mengetahui sejarah masjid tersebut. Sedangkan data sekunder diperoleh dari dokumen-dokumen yang terkait baik dari kajian pustaka cetak maupun elektronik seperti: buku, artikel jurnal ilmiah, situs website pemerintah kota Bandung, dan sebagainya.

Penelitian ini berlokasi di Masjid Al Imtizaj yang terletak di Jalan Banceuy nomor 8, kota Bandung. Masjid tersebut diresmikan pada tanggal 6 Agustus 2010 oleh Gubernur Jawa Barat saat itu, R. Nuriana. Bangunan masjid merupakan bentuk revitalisasi bangunan sebelumnya yakni bekas gudang sebuah pus at perbelanjaan di Bandung. Kemudian difungsikan lain untuk tempat peribadatan kaummus lim. Bangunan berdiri pada lahan milik pemerintah propinsi Jawa Barat seluas $133 \mathrm{~m}^{2}$. Masjid berkapasitas 200 orang yang memiliki tampilan yang unik karena hasil akulturasi budaya yang berbeda.

\section{HASIL DAN PEMBAHASAN}

\section{Hasil}

Masjid Al Imtizaj merupakan salah satu masjid yang memiliki bentuk yang unik. Hal ini didasari keinginan menambah seni bangunan masjid dengan budaya Tionghoa dan meningkatkan khazanah pembauran etnis Tionghoa Islam dengan umat Is lam lainnya. Pembangunan masjid ini sendiri dikomandani oleh Ir Danny Swardhani MBA, yang dikenal sebagai arsitek yang banyak membangun masjid, termasuk masjid Atta'awun Puncak, Bogor. Masjid Al Imtizaj mempunyai arti 'Pembauran' atau dalam bahasa Tionghoa yaitu 'Ronghe'. Hal ini sejalan dengan keadaan bahwa saat itu, mulai terbentuk beberapa komunitas muslim Tionghoa di Bandung, antara lain Persatuan Islam Tionghoa Is lam (PITI), Keluarga Persaudaraan Is lam (KPI), dan Yayasan Ukhuwah Mualaf Indonesia (YUMI). Mereka kemudian melebur dalam organisasi Ikatan Persaudaraan Tionghoa Is lam (IPTI).

Bangunan masjid ini sangat unik dan menarik. Didominasi warna etnis Tionghoa namun berkubah seperti masjid pada umumnya. Pada bagian entrance (pintu masuk) berupa gapura dengan beberapa lampion digantung hampir mirip gapura kelenteng. Bagian entrance didominasi warna merah, kuning, dan keemasan. Tempat wudu yang unik terletak di pelataran masjid berbentuk cawan emas turut menghiasi masjid. Selain itu di pelataran juga terdapat beberapa tempat
Gorga : Jurnal Seni Rupa

Volume 09 Nomor 02 Juli-Desember 2020

p-ISSN: 2301-5942 | e-ISSN: 2580-2380

duduk yang nyaman. Pohon dan bunga menghiasi setiap sudut Masjid Al Imtizaj.

Pada interior masjid didominasi warna yang sama dengan warna luar bangunan, merah, kuning, dan emas. Selain warna-warna tersebut sebagai aks en dihadirkan ornamen khas oriental Tiongkok bersanding dengan kaligrafi lafas asma Alloh. Selain itu juga ada mimbar dan gelaran sajadah.

Untuk area salat dibagi menjadi dua, laki-laki dan wanita. Dari pintu gerbang para jamaah laki-laki harus menuruni beberapa anak tangga untuk memasuki tempat wudu dan tempat salat. Sedangkan bagiwanita harus naik ke lantai dua.

\section{Pembahasan}

Seperti arsitektur masjid di Indonesia pada umumnya selalu menghadirkan kubah pada bagian puncak atapnya (kemuncak). Dimana alasan pemakaian kubah pada arsitektur masjid di Indonesia tidak lain karena ingin meniru penampilan kubah yang dilihat pada bentuk aslinya. Sebab keindahan masjid muncul sebagai satu kesatuan bentuk dengan penonjolan pada bentuk kubahnya. Sedangkan kubah sendiri sebagai aspek estetika yang menjadi titik rangkap utama, s ehingga seolah-olah kubahlah y ang berkesan pada saat orang melihat masjid.

Kubah merupakan bagian bangunan sebagai hasil dari pembauran arsitektur Islam dan Barat melalui seni arsitektur Byzantium. Fungsi kubah sebenamya sebagai penutup ruang utama atau ruang inti yang merupakan titik sentral pada bangunan masjid. Dilihat dari segi kepentingan arsitektur, kubah merupakan sebuah penonjolan bentuk yang dapat menambah indah arsitektur masjid.

Penempatan kubah pada arsitektur masjid Al Imtizaj berbeda dengan masjid-masjid lainnya. Kubah diletakan pada atap pintu gerbang masjid yang berada di pinggir trotoar. Dimana bentuk atap pintu gerbang ini menyerupai bentuk atap kelenteng, namun puncaknya diberi kubah. Mengingat bangunan masjid menyesuaikan dengan kondisi eks is ting bangunan awal sebelum direvitalisasi untuk masjid. Keberadaan kubah pada pintu gerbang juga sebagai penegasan bahwa bangunan ini adalah bangunan masjid tempat ibadah kaum muslim.

Bentuk kubah emas di atas gerbang berbentuk lingkaran merupakan akulturasi dari budaya Islam dengan budaya Tionghoa. Kubah sebagai penanda masjid mewakili budaya Islam. Sedangkan pintu lingkaran mewakili budaya Tionghoa. 


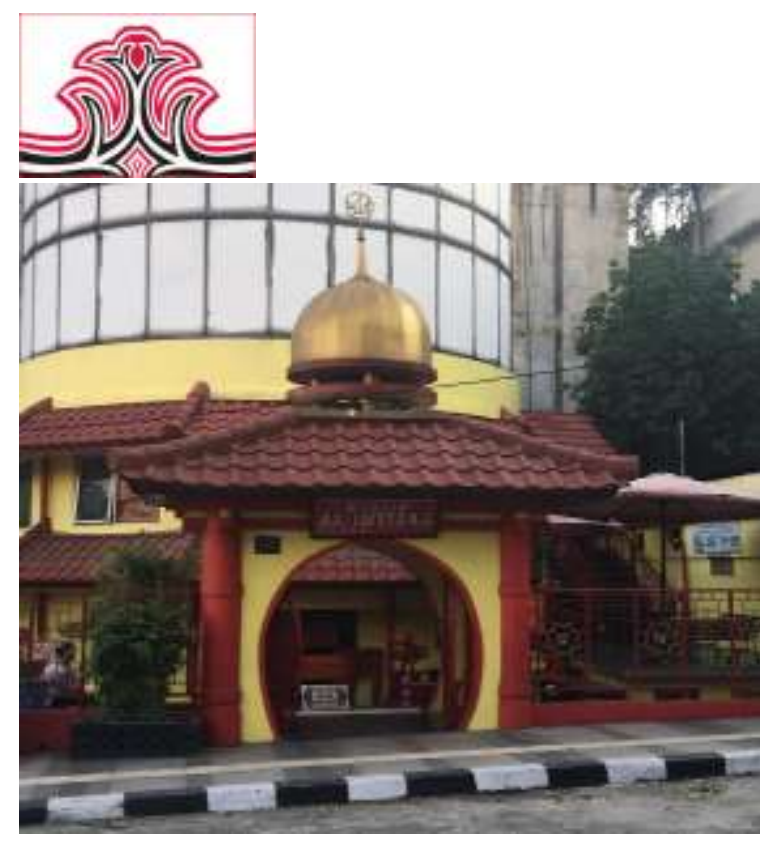

Gambar 1. Kubah pada pintu masuk masjid Al Imtizaj. (Sadono, 2020)

Bagian ruang utama yang terpenting pada masjid adalah mihrab yaitu tempat seorang imam memimpin shalat. Pada umu mnya mas jid di Indonesia kebanyakan menghadap ke Timur, sedangkan mihrabnya menghadap ke arah Barat. Begitupula mihrab dalam masjid Al Imtizaj menghadap ke arah Barat yang mengarah pada Masjidil Haram, Mekkah. Hal ini mencerminkan kebudayaan Islam yang mengharuskan arah hadap mihrab kepada Masjidil Haram, Mekkah. Bentuk pembatas mihrab dengan area sholat jemaah dibuat seperti bentuk entrance masjid yang memiliki bentuk das ar lingkaran namun distilasi.

Dinding pembatas dengan bukaan pintu berbentuk lingkaran merupakan pengaruh budaya Tionghoa. Bangsa Tionghoa mengenal ajaran Lao Tzu, bahwa ruang yang terkandung di dalamnya adalah lebih hakiki ketimbang materialnya, yakni massa. Ajaran tersebut menekankan pada batasan antara ruang internal dan eksternal yaitu dinding pemisah. Ia menjelaskan kekosongan yang terbingkaikan oleh pintu dan jendela yang boleh dianggap sebagai ruang transisi yang membatasi bentuk arsitektur (Ven, 1991). Di negara Tiongkok penerapan ajaran tersebut sering dihadirkan juga dalam unsur bangunan yakni pintu gerbang yang berbetuk lingkaran besar yang dibingkai. Bentuk inipun juga dimunculkan pada bagian entrance (pintu gerbang) dan pembatas antara mihrab dengan area jamaah.
Gorga : Jurnal Seni Rupa

Volume 09 Nomor 02 Juli-Desember 2020 p-ISSN: 2301-5942 | e-ISSN: 2580-2380

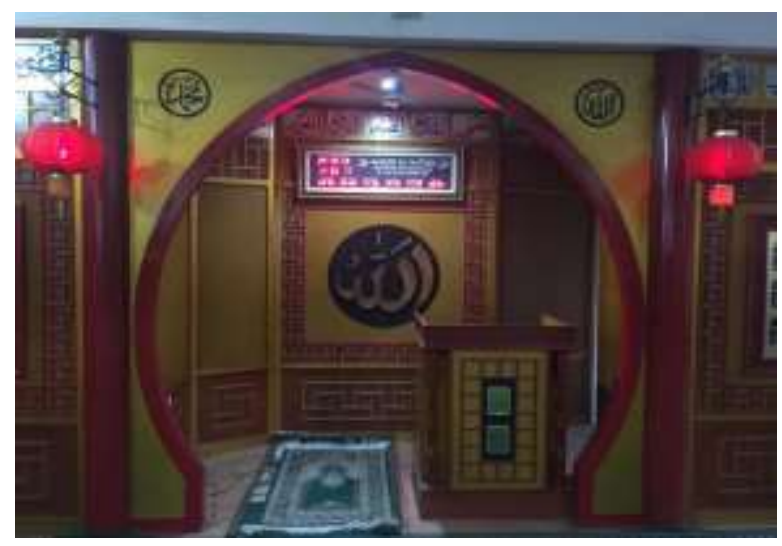

Gambar 2. Mihrab masjid Al Imtizaj Cikapundung Bandung. (Sadono, 2020)

Hal lainnya yang menjadi ciri khas budaya Tionghoa adalah pemakaian ornamen dalambangunan. Ornamen adalah ragam hias untuk suatu benda, pada dasamya merupakan suatu pedandan atau kemolekan yang dipadukan. Ragam hias berperan sebagai media untuk mempercantik atau mengagungkan suatu karya. Dekoratif dan ornamen tidak saja menghadirkan estetika.

Kultural dan historikal tetapi dapat pula terbentuk melalui permukaan atap, permukaan dinding, ataupun permukaan langit-langit. Unsur dekoratif dan ornamen biasanya lebih memberikan gambaran tentang imajinasi manusia yang dituangkan dalam keadaan nyata. Pada awal perkembangan pembangunannya, masjid juga tidak terlepas dari ornamen. Dahulu, pemakaian ornamen pada masjid tidak terlalu menonjol, karena pada masa itu, umat muslim Indonesia memiliki pengertian bahwa masjid harus ditampilkan dalam bentuknya yang sesederhana mungkin, sehingga pemakaian hias an hanya terbatas pada tempat-tempat tertentu, misalnya pada mimbar dan serambi masjid (Toekio, 1987).

Menurut Rochym, kini ornamen dan ragamhias lainnya sudah semakin berkembang, salah satu yang berkembang pesat adalah seni ukir kayu yang merupakan penerusan dari kecakapan para seniman dalam seni pahat patung. Demikian pula hiasan ornamen yang terdapat pada mimbar masjid, biasanya terbuat dari kayu dan bernilai seni tinggi. Dalam arsitektur masjid Al Imtizaj, terdapat beberapa ornamen yang mempercantik bangunan masjid.

Ornamen pada mimbar di bagian mihrab. Pada bagian mihrab di masjid Al Imtizaj Bandung, terdapat ornamen bertulis kan huruf Arab y ang memperlihatkan unsur budaya Arab yang tetap ada pada masjid ini walaupun berbentuk mirip kelenteng. Mimbar dan ornamen tersebut terbuat dari kayu. Hal ini 


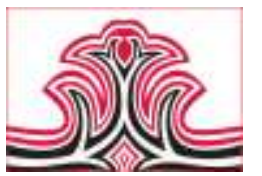

menunjukkan bahwa seni ukir kayu biasanya digunakan sebagai ornamen masjid.

Ornamen bertulisan Allah dan tulisan Al-Quran ini merupakan upaya agar setiap hamba untu mengingat kepada Allah. Ornamen ini dipajang dengan menggunakan bingkai agar terlihat lebih artistik sekaligus untuk melindungi dari kotoran dan debu. Dani sini, sangat terlihat jelas perpaduan antara Is lam dan budaya Tionghoa, yaitu melalui bentuk tulisan di dinding masjid. Selain ornamen kaligrafi pada interior masjid ju ga terdapat ornamen motif batu bata. Ornamen ini ini mengingatkan pada bangunan tradisional Tionghoa dimana batu bata sering digunakan untuk lantai.

Ciri khas pengaruh budaya Tionghoa pada bangunan masjid ini selain bentuk dan pemakaian ornamen adalah penerapan warna. Warna didominasi dengan warna khas merah, kuning, dan keemasan. Seperti pada bangunan kelenteng yang ada di Tiongkok, warna mempunyai makna simbolis. Menurut Handinoto warna merah menyimbolkan warna api dan darah, yang dihubungkan dengan dengan kemakmuran dan keberuntungan. Merah juga simbol kebajikan, kebenaran, dan ketulusan. Warna merah juga dihubungkan dengan arah, yaitu arah selatan, dan sesuatu yang positif. Itulah sebabnya warna merah sering dipakai dalam arsitektur Tionghoa (Handinoto, 2009). Warna merah melambangkan kemakmuran dan keberuntungan sedangkan warna kuning melambangkan kekayaan.

Namun hal ini tidak berlaku pada bangunan masjid Al Imtizaj dimana penggunaan warna merah dan kuning ini dimaksudkan hanya sebagai bentuk adaptasi budaya saja. Warna-warna tersebut sengaja digunakan dengan maksud agar warga Tionghoa yang datang ke masjid ini merasa lebih nyaman dan familiar. Hal ini mengingat beberapa jamaah merupakan para mualaf yang berasal dari etnis Tionghoa.

Seperti juga nama Al Imtizaj atau dalam bahasa Tionghoa 'Ronghe' yang berarti pembauran. Maka desain interior dan arsitektur masjid juga memakai beberapa warna yang sangat kental dengan budaya Tionghoa namun tidak terikat oleh makna simbolik warna.
Gorga : Jurnal Seni Rupa

Volume 09 Nomor 02 Juli-Desember 2020 p-ISSN: 2301-5942 | e-ISSN: 2580-2380

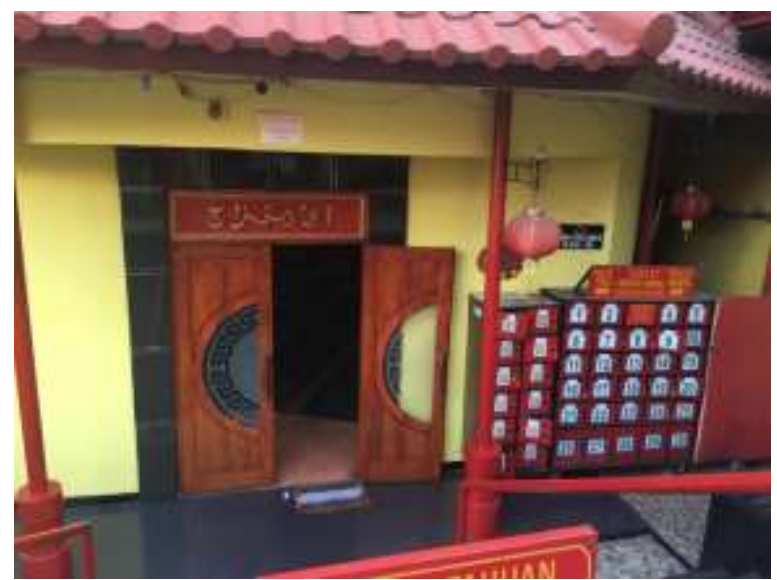

Gambar 3. Ornamen depan pintu masjid Al Imtizaj Cikapundung Bandung. (Sadono, 2020)

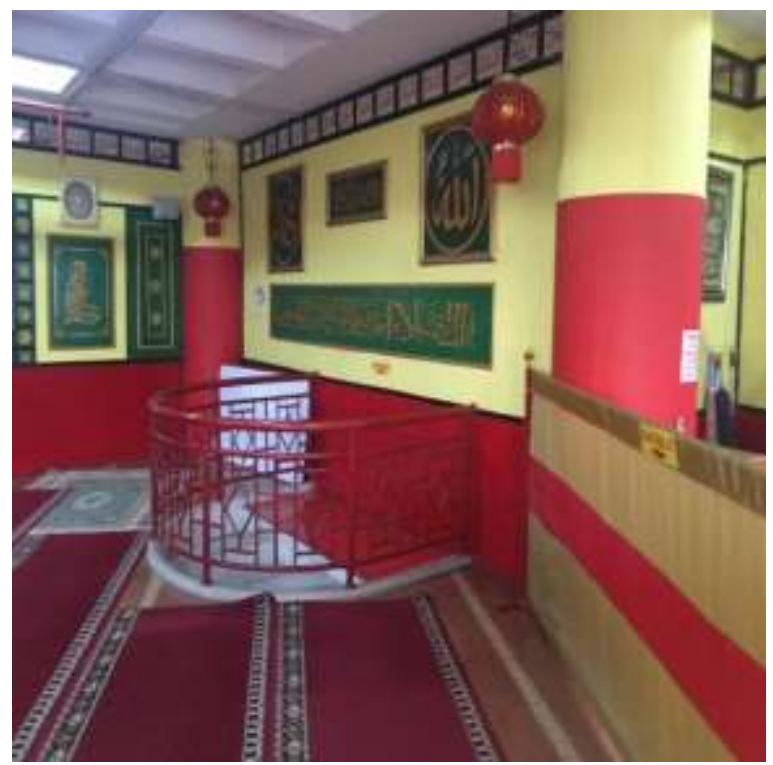

Gambar 4 . Ornamen tulisan masjid Al Imtizaj Cikapundung Bandung. (Sadono, 2020)

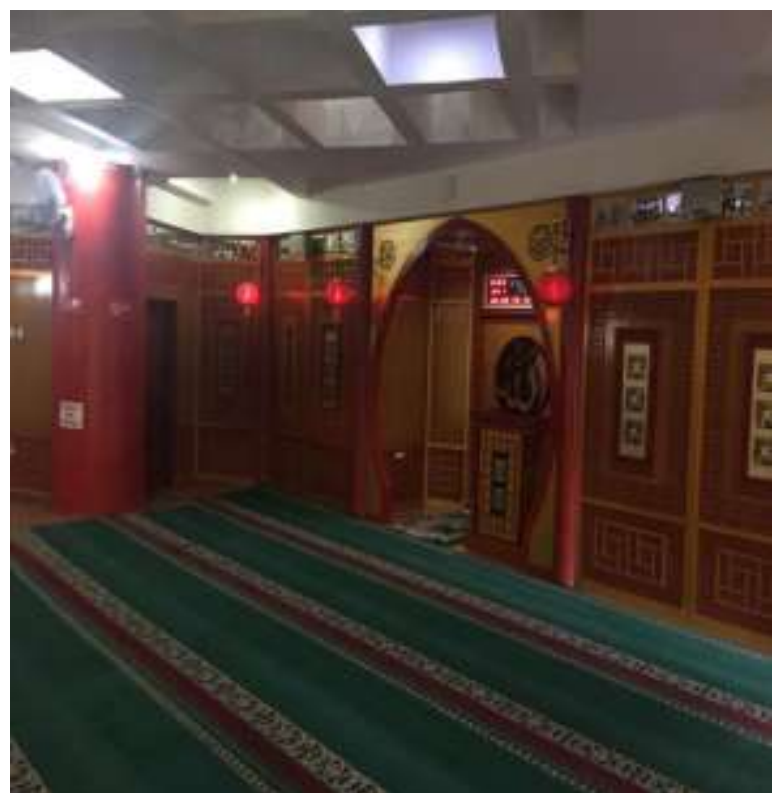

Gambar 5. Ornamen warna masjid Al Imtizaj Cikapundung Bandung. (Sadono, 2020) 


\section{KESIMPULAN DAN SARAN}

1.Kesimpulan

Arsitektur masjid di Indonesia telah mengalami perubahan dari masa ke masa. Dahulu, ketika penganuh agama Hindu sangat kuat di Indonesia, arsitektur masjid-masjid juga tak luput dari pengaruh budaya tersebut. Sekarang, sudah banyak masjid-masjid yang didirikan dengan arsitektur yang beragam, kebanyakan bentuk bangunannya bergay a Timur Tengah. Tetapi, di Bandung, terdapat masjid yang dalam arsitektumya bergaya Tionghoa, yaitu masjid Al Imtizaj. Adanya masjid ini tentu tidak lepas dari peranan muslim Tionghoa di Indonesia.

Masjid yang dires mikan untuk umum pada tanggal 6 Agustus 2010 didasari atas keinginan Gubernur Jawa Barat saat itu untuk menambah khasanah seni bangunan masjid dengan budaya Tionghoa sekaligus menjadi tanda pembauran etnis Tionghoa Is lam dengan umat muslim lainnya. Sesuai dengan namanya masjid AlImtizaj yang berarti 'Pembauran' atau dalambahasa Tionghoa 'Ronghe' bangunan ini memiliki ciri khas percampuran budaya Tionghoa, Islam, dan Arab. Percampuran budaya tersebut menjadi bukti akulturasi budaya dalam arsitektur masjid Al Imtizaj.

Akulturasi tersebut adanya unsur-unsur pada bentuk, pemakaian ornamen dan warna. Unsur-unsur bangunan tersebut sebagai bentuk adaptasi budaya dengan maksud ag ar warga Tionghoa yang datang ke tempat ini merasa lebih nyaman dan diterima.

\section{Saran}

Keragaman budaya yang ada di Nusantara dapat menjadi referensi untuk perancangan arsitektur maupun desain interior masa kini. Perancangan bangunan baru diharapkan tidak lepas dari kebiasaan dan kemampuan masyarakat / komunitas yang mendukungnya.

\section{DAFTAR RUJUKAN}

Atno. (2000). Teori Masuknya Agama dan Budaya Islam ke Indonesia. https://news .detik.com/berita/D-4728897/15kerajaan-Islam-di-Indonesia-danPeninggalannya (diakses tanggal 28 Maret 2020).

Ayuningrum, Diah. (2017). Akulturasi Budaya Cina dan Is lam Dalam Arsitektur Tempat Ibadah di Kota Lasem, Jawa Tengah. Jurnal Sabda, 12 (2), 122-135.

Damayanti, Risca, Triyanto Triyanto, \& Muh. Ibnan Syarif. (2016). Masjid Jami'Piti Muhammad Cheng Hoo Purbalingga: Refleksi Akulturasi
Gorga : Jurnal Seni Rupa

Volume 09 Nomor 02 Juli-Desember 2020 p-ISSN: 2301-5942 | e-ISSN: 2580-2380

Budaya Pada Masyarakat Purbalingga. Jurnal Carthasis, 5(2), 99-106.

Handinoto. (2009). Perkembangan Arsitektur Tionghoa di Indonesia. Jakarta : PT Intisan

Mediatama dan Komunitas-Lintas Budaya Indonesia.

Hasjmy. (1993). Sejarah Kebudayan Islam di Indonesia. Jakarta: Bulan Bintang.

Kutoyo, S., et al. (1999). Peninggalan Situs dan Bangunan Bercorak Islam di Indonesia. Jakarta: PT Mutiara Sumber Widya.

Koetjaraningrat. (1985). Bunga Rampai-Kebudayaan Mentalitas dan Pembangunan. Jakarta: PT Gramedia.

Mulyana, Deddy \& Rakhmat Jalaluddin. (2006). Komunikasi Antarbudaya. Bandung: PT Remaja Rosdakarya.

Qurtuby, Sumanto Al. (2017). Arus Cina-Islam-Jawa: Peranan Tionghoa dalam Penyebaran Islam di Nusantara Abad 15 \& 16. Semarang: eLSA Press.

Rochym, A. (1995). Mesjid dalam Karya Arsitektur Nasional Indonesia. Bandung: Angkasa.

Sadono, S. (2020). "Ornamen Masjid Al Imtizaj Cikapundung Bandung". Hasil Dokumentasi Pribasi: 17 Mei 2020, Masjid Al Imtizaj Bandung.

Roszi, Jurna Petri. (2018). Akulturasi Nilai-nilai Budaya Lokal dan Keagamaan dan Pengaruhnya Terhadap Perilaku-perilaku Sosial. FOKUS: Jurnal Kajian Keislaman dan Kemasyarakatan, 3(2), 171-198.

Suhandinata, Justian. (2009). WNI Keturunan Tionghoa Dalam Stabilitas Ekonomi dan Politik Indonesia. Jakarta: PT Gramedia Pustaka Utama.

Toekio, S. (1987). Mengenal Ragam Hias Indonesia. Bandung: Angkasa.

Ven, Cornelis van de. (1991). Ruang Dalam Arsitektur. Jakarta: PT Gramedia Pustaka Utama. 